Artigo recebido em: 17.10.2017

Aprovado em: 14.05.2018

Bárbara Maia

Doutoranda pelo Programa de PósGraduação em Comunicação da UERJ. Mestre pelo PPGCOM da UFPR. Bolsista Faperj. E-mail: barbaramaiap@ gmail.com

${ }^{1}$ Artigo apresentado originalmente no $15^{\circ}$ Encontro Nacional de Pesquisadores em Jornalismo - SBPJor Associação Brasileira de Pesquisadores em Jornalismo, ECA/USP - São Paulo

- Novembro de 2017.

Estudos em Jornalismo e Mídia Vol. 15 No 1 Janeiro a Junho de 2018 ISSNe 1984-6924

\section{As transformações no ethos do jornalista: a reformulação dos valores profissionais perante um cenário de convergência ${ }^{1}$}

\author{
Bárbara Maia
}

\section{Resumo}

A presente pesquisa objetiva analisar como os jornalistas identificam as mudanças no ethos profissional e quais novos valores surgem presentes no fazer jornalístico. Como base teórica utiliza-se os conceitos de convergência de mídias, ethos profissional, newsmaking, rádio expandido e profissional multifunção. O desenvolvimento empírico da pesquisa se dá com o recorte dos resultados obtidos na dissertação de mestrado da autora, defendida no início de 2017. Destaca-se, como principal resultado da análise, a identificação de que, apesar de alguns tradicionais valores profissionais ainda estarem presentes na prática jornalística, outros desaparecem do discurso dos profissionais e novos valores surgem como balizadores nas redações.

Palavras-chave: Ethos. Valores. Convergência de mídias.

The transformations on the journalist's ethos: the reformulation of professional values upon a convergence cenary

\begin{abstract}
This current research aims to analyze how journalists identify changes on the professional ethos and which values emerge in journalism. As a theoretical base, concepts of media convergence, professional ethos, newsmaking, expanded radio and multifunctional professional are used. The empirical development is given by excerpts from the results obtained from the author's master's dissertation, presented at the beginning of 2017. As a main result, even though some traditional values are still present in journalistic duties, other disappear from the speech of professionals and new values arise as indicators at newsrooms.
\end{abstract}

Keywords: Ethos. Values. Media convergence. 


\section{Introdução}

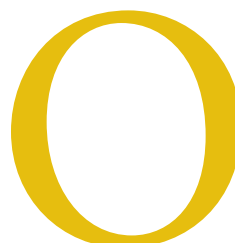

conceito de convergência de mídias tem sido exaustivamente trabalhado pelos pesquisadores da comunicação nos últimos anos, seja pelo viés do jornalismo digital (QUADROS, 1999; PALACIOS, 2011; MIELNICZUK, 2004), seja com abordagens da cibercultura (PRIMO, 2010; RÜDIGER, 2013) ou com o foco em meios de comunicação específicos, como o rádio (KISCHINHEVSKY, 2007; PRATA, 2008; LOPEZ, 2009; FERRARETTO, 2010). Porém, apesar da diversidade de pesquisas, considera-se pertinente apresentar uma discussão que traga o jornalista como ponto central, analisando de que forma a convergência de mídias, que é um fenômeno que ocorre pelo "fluxo de conteúdos através de múltiplas plataformas de mídia, à cooperação entre múltiplos mercados midiáticos e ao comportamento migratório dos públicos dos meios de comunicação" (JENKINS, 2009, p. 29), modifica a realidade deste profissional.

Ressalta-se, todavia, que houve importantes pesquisas no campo que se dedicaram a entender a realidade dos jornalistas frente ao cenário convergente. Destacam-se, entre elas, as pesquisas realizadas pelas pesquisadoras Sylvia Debossan Moretzsohn (2014), com visitas realizadas à redação do jornal O Globo; Roseli Fígaro (2013), com extenso estudo dos jornalistas na cidade de São Paulo; e a tese da Nélia Del Bianco (2004), que especifica o meio radiofônico na análise. Contudo, mesmo utilizando estes trabalhos como referência, o recorte proposto na presente pesquisa difere-se das citadas por especificar mudanças no ethos profissional, ou seja, verificar se os hábitos profissionais mudaram perante as transformações do mercado e as tecnologias, e de que forma isto reconfigurou a relação dos jornalistas com a profissão e com os valores definidores da prática.

Como base teórica para o desenvolvimento deste artigo utiliza-se a junção de dois operadores teóricos centrais, a convergência e a teoria jornalística do newsmaking (WOLF, 1999; PENA, 2005). Enquanto a convergência propõe verificar as mudanças ocorridas no âmbito tecnológico, mercadológico (econômico) e social, o newsmaking especifica "a cultura profissional dos jornalistas, a organização do trabalho e os processos produtivos" (PENA, 2005, p. 129), embasando, portanto, a análise da estrutura funcional de uma redação radiofônica. Além disso, a teoria possibilita uma abordagem mais ampla sobre a problemática proposta, visto relacionar os valores profissionais ao âmbito organizacional e produtivo, necessários para a compreensão das especificidades presentes no objeto analisado.

Os resultados empíricos são fruto da dissertação de mestrado desenvolvida junto ao Programa de Pós-Graduação em Comunicação da Universidade Federal do Paraná (MAIA, 2017). Na pesquisa, foram realizadas nove entrevistas semiabertas com antigos e atuais jornalistas contratados da $C B N$-Curitiba. A escolha por uma emissora radiofônica ocorreu por considerar que o meio contém dois aspectos primordiais: 1) ser tradicional e centenário, que já superou diversas dificuldades ao longo dos anos, a exemplo do surgimento da televisão; 2) ser relevante, ganhando novas características e produzindo para novas plataformas. Assim, a $C B N$-Curitiba, primeira rádio all news do Paraná, surgiu como primeira opção para realização da pesquisa.

Os resultados obtidos na análise empírica trouxeram diversas discussões acerca da realidade dos profissionais entrevistados. Por isso, compreende-se necessário, em um primeiro momento, realizar a conexão teórica existente entre os conceitos que servem de base para o desenvolvimento do presente artigo. Assim será possível tecer um quadro teórico que permitirá interpretar os dados obtidos. 


\section{Convergência e Newsmaking}

A convergência de mídias é abordada aqui pelo seu viés multidimensional, ou seja, consideram-se as mudanças tecnológicas, porém relacionando-as com as de cunho econômico, social e cultural. Com isso, utiliza-se de dois autores que, apesar de serem criticados por possuírem uma abordagem deveras otimista quanto ao cenário atual, trazem considerações importantes sobre os efeitos das transformações nos meios de comunicação: Roger Fidler (1998) e Henry Jenkins (2009). Apesar de percorrerem caminhos similares no tratamento dado às mudanças citadas, ambos possuem concepções diferentes. Enquanto o primeiro propõe a midiamorfose como conceito de compreensão deste cenário, o outro apresenta a convergência midiática e seus efeitos no cenário de fãs. Contudo, mesmo os tendo como centrais na discussão, é preciso considerar que o conceito descrito já percorreu diversos caminhos teóricos, que vão desde:

a integração sistêmica baseada na eletrônica digital nos anos 1970 (POOL, 1983) à sobreposição industrial nos anos 1980 (NEGROPONTE, 1995), das múltiplas mídias e Internet nos anos 1990 (LÉVY, 1993), mudanças político/econômicas, culturais e sociais nos anos 2000 (JENKINS, 2006) às formas estendidas de narrativa transmidiática atuais (JENKINS, 2009; JENKINS; GREEN; FORD, 2014) (TÁRCIA, 2015, p. 23).

A acepção deste percurso é importante não apenas para o entendimento da evolução do tema, mas também do contexto no qual estão inseridos os meios de comunicação, mais especificamente o rádio. Entretanto, antes é necessário discorrer sobre outro importante conceito aqui utilizado, que proporcionará um abarcamento amplo das circunstâncias pesquisadas, o newsmaking.

Newsmaking é uma teoria jornalística fundamentada em uma estrutura construtivista que tem como base três aspectos principais: "a cultura profissional dos jornalistas, a organização do trabalho e os processos produtivos" (PENA, 2005, p. 129). A teoria se propõe a analisar como os critérios de noticiabilidade estão relacionados a estes aspectos, ou seja, para compreender como as notícias são escolhidas pelos jornalistas, "é necessário conhecer não apenas os sistemas de valores, de representações, de imaginário colectivo que eles propõem, mas também o modo, os processos, as restrições e as limitações em que tudo isso acontece" (WOLF, 1999, p. 80).

Apesar dos dois conceitos terem desenvolvimentos distintos e relacionarem-se a realidades diferentes (a convergência possui uma abordagem multidimensional, enquanto o newsmaking centra-se no jornalismo), ambos podem ser complementares na percepção do mundo do jornalista como uma realidade profissional em mutação. A convergência de meios acaba por estimular mudanças na realidade estudada pelo newsmaking, ou seja, nas relações produtivas e profissionais. Tais transformações fazem necessário rever algumas abordagens, como "a lógica dos processos pelos quais a comunicação de massa é produzida e o tipo de organização do trabalho dentro da qual se efectua a construção das mensagens" (WOLF, 1999, p. 78), aspectos que passaram por modificações profundas após a inserção das tecnologias digitais na rotina produtiva e pelas reconfigurações econômicas e organizacionais. Alguns conceitos, portanto, tornam-se basilares para o desenvolvimento aqui proposto, como o jornalista multifunção/multimídia e o rádio expandido.

Com a desregulação dos cargos antes presentes nas redações, a exemplo do editor de áudio, a precarização da profissão do jornalista e o surgimento de novas demandas de trabalho, atreladas às tecnologias digitais, o jornalista se vê diante de um mercado que exige profissionais multifunção, ou seja, que se encarregam não 
apenas das demandas referentes ao cargo ocupado, mas que absorvam as relativas aos extintos cargos técnicos, produzam para diferentes plataformas e que estejam disponíveis para suprir as necessidades surgidas em decorrência de faltas ou doenças. Estas características foram observadas por Moretzsohn (2014) em pesquisa realizada na redação do jornal $O$ Globo.

O vídeo que $O$ Globo (2014b) divulgou para mostrar sua aposta na valorização do digital é enganoso. O "novo ritmo da redação" é muito mais acelerado que o anterior, como seria previsível e ficou claro nos depoimentos aqui expostos. Os nervos continuam à flor da pele e o esgotamento ao fim do dia é inevitável. Talvez ainda maior do que era antes, e não porque "o meio internet tem menos pausas", mas porque a empresa ainda não conseguiu estabelecer uma rotina que evite a sobrecarga diante desse meio (MORETZSOHN, 2014, p. 76)

Esta demanda por profissionais multifunção, que produzam para diversas plataformas e que atuem como técnicos, dada a facilidade ao acesso a tecnologias de edição disponibilizadas por preços ínfimos ou até mesmo gratuitos, pode ser melhor explicada pelo conceito de rádio expandido, o qual considera que o rádio "extrapola as transmissões em ondas hertzianas e transborda para as mídias sociais, o celular, a TV por assinatura, sites de jornais, portais de música" (KISCHINHEVSKY, 2016, p. 13). A explicação centra-se no fato de que essa expansão do meio radiofônico traz novas demandas ao jornalista, que deve se adaptar não apenas à reformulação do meio, mas também a exigências profissionais excessivas e a um mercado pulverizado, que não sabe mais identificar onde encontra-se sua audiência e o que caracteriza este novo perfil.

\section{O ethos do jornalista}

A profissão do jornalista é envolvida por uma série de ideais que, inicialmente, permeiam aquilo que norteia o fazer jornalístico. "O jornalismo foi definido como o preenchimento de certas funções na sociedade, ou, se preferirem, no cumprimento de papeis sociais bem precisos" (TRAQUINA, 2012, p. 130). Tais papéis fundam-se na ideia de uma estrutura democrática, que tem como princípio basilar a divergência e a diversidade de opiniões. $O$ jornalista seria então o responsável em realizar a ponte entre a fonte das informações, os acontecimentos e a sociedade civil. "O jornalismo, inicialmente identificado como imprensa, deve ser um veículo de informação para equipar os cidadãos com as ferramentas vitais ao exercício dos seus direitos" (TRAQUINA, 2012, p. 130).

Porém, é preciso frisar que o ethos jornalístico vai além de definições profissionais, abarcando também os acordos sociais frisados entre quem enuncia e o interlocutor. Lisboa (2012), por exemplo, propõe que a credibilidade, importante valor profissional, deve ser analisada através de duas facetas distintas: a credibilidade constituída e a percebida, ou seja, aquela de quem enuncia e a atribuída pelo receptor. "A credibilidade constituída de um orador precisa preexistir à percepção do interlocutor, mas só ganha sentido dentro de uma relação intersubjetiva" (LISBOA, 2012, p. 15). Assim sendo, entende-se que o ethos do jornalista é anterior e não está atrelado ao ato de enunciação (LISBOA; BENETTI, 2015) pois o ethos pré-discursivo do jornalismo implica uma presunção de credibilidade (BURGE, 1993), ou seja, há uma construção de representação antes mesmo da fala do enunciador.

Por isso é importante analisar além deste ethos, que é afirmado há mais de 150 anos (TRAQUINA, 2012), os valores compartilhados pelos jornalistas com 
seus pares, que normatizam o fazer profissional. Entre os principais estão a liberdade e a objetividade. A liberdade pode ser relacionada ao ethos do jornalista como membro fundante de uma democracia, ou seja, como uma estrutura fiscalizadora e crítica. Este valor está relacionado também à independência e à autoridade, que fortalecem a credibilidade do jornalista perante a sociedade, principalmente no que se refere à confiança na veracidade das informações veiculadas (TRAQUINA, 2012). Estes valores estão vinculados à profissão desde o século XIX, período em que a imprensa de massa surge em um cenário de transformações industriais, políticas e sociais profundas (ORTIZ, 1991). Já a objetividade "nasceu no jornalismo no século XX, mas surgiu como base em uma mudança fundamental do jornalismo, que ocorreu no século XIX, em que a primazia era dada aos fatos, e não às opiniões" (TRAQUINA, 2012, p. 137). Porém, ainda no século XX, este valor sofreu algumas reconfigurações em sua interpretação, principalmente por um entendimento de que havia muitas subjetividades envolvidas no fazer jornalístico, sendo, portanto, tal meta inalcançável (TRAQUINA, 2012). Lippmann (1922, p. 256) discorre sobre estas reflexões, ao afirmar que "enquanto a nossa mente se torna ainda mais consciente da sua própria subjetividade, encontramos um sabor especial no método objetivo".

Contudo, a imparcialidade não foi o único valor que sofreu reconfigurações ao longo dos anos. As transformações no campo profissional do jornalista trouxeram diversos desafios e novos modos de fazer, junto a mudanças na definição identitária do próprio jornalista, que passa a se ver e a ser visto de forma menos romântica e mais taylorizada. Com o objetivo de compreender estas novas significações, utiliza-se como análise empírica a entrevista semiaberta com nove jornalistas radiofônicos. Busca-se analisar, nos resultados obtidos, o discurso individual dos jornalistas quanto aos valores que regem sua profissão.

\section{Pesquisa empírica}

A pesquisa empírica, desenvolvida para a dissertação de mestrado da presente autora, foi realizada no período de agosto e setembro de 2016, na cidade de Curitiba. O método utilizado foi a entrevista semiaberta, que tem como característica principal a criação de um roteiro aberto de perguntas, em que as respostas dadas pelos entrevistados determinam as próximas perguntas a serem realizadas. "A lista de questões desse modelo tem origem no problema de pesquisa e busca tratar da amplitude do tema, apresentando cada pergunta de forma mais aberta possível" (DUARTE, 2015, p. 66).

O corpus analisado foi composto por nove jornalistas, dentre os quais cinco eram antigos funcionários da rádio CBN-Curitiba e quatro atuais. A seleção destes perfis relacionou-se ao objetivo da pesquisa, de compreender quais foram as mudanças que ocorreram ao longo dos anos na emissora, frente à convergência de meios. O roteiro foi composto por 16 perguntas, o que excedeu a média proposta para uma entrevista semiaberta, de sete perguntas. Porém, compreendeu-se que desta forma seria possível criar vínculo de confiabilidade com os entrevistados, deixando-os mais à vontade para responder as perguntas mais complexas.

Após o emprego do roteiro, aplicou-se uma metodologia de análise, visto a

${ }^{2} A$ opção por codinomes foi inspirada na pesquisa realizada para o livro "As Mudanças no Mundo do Trabalho do Jornalista", organizado por Roseli Fígaro, Cláudia Nonato e Rafael Grohmann (2013). necessidade de sistematizar os dados obtidos. Optou-se, neste sentido, pela análise de conteúdo (BARDIN, 2016). Foram estipuladas três categorias de análise e, em cada uma delas, três categorias de contexto. Na categoria relações profissionais, encontra-se a denominada "valores profissionais", analisada neste artigo. Para evitar exposição desnecessária dos entrevistados, optou-se por descrevê-los através de codinomes ${ }^{2}$ o jornalista que atua em diversas frentes, o jornalista com tempo 
de rádio, a jornalista recente no mercado, o jornalista que também é radialista, o jornalista que não atua mais como jornalista, a jornalista com vasta experiência, a jornalista que agora é docente, o jornalista que entende de rádio como ninguém e a jornalista que se lembra do rádio com carinho.

$\mathrm{Na}$ análise da categoria dos valores profissionais foram observadas duas variáveis: os valores que permeiam a profissão e os valores que permeiam o fazer jornalístico e sua relação financeira com as empresas. Nessa relação financeira, verificou-se correspondência aos baixos salários ofertados pelas empresas e a necessidade de os jornalistas procurarem, muitas vezes, uma segunda ou até mesmo terceira opção empregatícia. Havia, assim, a sobrecarga dos profissionais, que ficavam menos dispostos em exceder suas horas na empresa (prática que foi descrita como comum pelos entrevistados) ou produzir matérias que fugissem da exigência rotineira de um jornal local, algo evidenciado no discurso de uma das entrevistadas: "eu tinha de dois a três empregos em veículos de comunicação, então eu precisava ser muito rígida com meus horários para atender tudo o que eu queria fazer" (A jornalista com vasta experiência, 2016). Nestes casos, a robotização da rotina produtiva fez com que a jornalista se adaptasse sem críticas a uma realidade que mais se assemelhava à de um produtor de conteúdo.

Outra mudança percebida foi quanto aos valores que regem a profissão. Apesar de ainda identificarem a objetividade e a credibilidade como importantes, sublinharam que tais valores estão desaparecendo em um mercado que apenas se interessa pelo aumento da audiência e do investimento publicitário. Esta crítica focou-se principalmente na postura opinativa adotada por diversos jornalistas, que exprimiam comentários ao longo da veiculação da notícia.

O jornalismo se tornou uma arrogância cotidiana. $\mathrm{O}$ jornalismo não tem mais dúvida de nada, tem certeza de tudo. Quem tem certeza de tudo é um idiota. Tirando algumas exceções que têm por aí, você vê os jornalistas exercitando suas certezas, enquanto a nossa profissão é calcada na dúvida, na dúvida permanente, inclusive quanto a si. Quem não dúvida de si, da própria capacidade de análise, de observação, quem não se arma contra os próprios preconceitos, para que ele não contamine seu trabalho, vai produzir lixo ( $O$ jornalista que não atua mais como jornalista, 2016).

Os entrevistados, portanto, consideraram ser a criticidade um valor profissional, porém entendiam ser tal valor contrário a discursos opinativos. "Um jornalismo mais crítico não quer dizer linchador. Crítico é o que avalia, argumenta, pondera. Ninguém está interessado no que o jornalista acha. Opinião não é o que acho, opinião é argumento" (O jornalista que não atua mais como jornalista, 2016). Compreende-se assim que o valor da objetividade, relacionado à fé nos fatos (TRAQUINA, 2012), permanece no imaginário profissional. Entretanto, apesar de ainda se fazerem presentes na fala dos jornalistas, ambos os valores são incoerentes à rotina descrita pelos entrevistados, de exigência por apurações rápidas e produções superficiais, o que foi exposto por uma das entrevistadas:

Eu não tenho tempo de pensar uma super pauta. Eu jogo as coisas para os repórteres e eles que se virem. Aí quando as dificuldades vão surgindo eles vêm me procurar. Então eu não tenho uma produção para elas. Eu produzo o jornal porque penso o jornal de uma forma geral. Mas eu não consigo entregar uma pauta produzida para os repórteres (A jornalista com tempo de rádio, 2016).

Foi identificado também que alguns entrevistados compreendiam que a qualificação profissional era uma questão importante, principalmente na apreensão de novas funções: "eu sou repórter, se precisar eu sou um âncora, se precisar 
${ }^{3} A$ decisão pela não obrigatoriedade do diploma de jornalismo foi realizada pelo STF em 2009. O argumento utilizado pelos ministros foi de que o decreto de lei que regulamenta a profissão foi instituído

durante o regime militar e tinha como finalidade afastar do jornalismo os intelectuais contrários ao regime. faço produção" (O jornalista que entende de rádio como ninguém, 2016). Porém, neste caso, pode-se haver a utilização deste interesse pelas empresas para justificar a sobrecarga dos jornalistas e o não cumprimento dos direitos trabalhistas que regem a profissão, fazendo com que o jornalista assuma diversos papéis na redação com a justificativa de aprender, sanando problemas que a empresa deveria assumir, principalmente com a contratação de um número superior de profissionais e com a valorização dos contratados. Esta condição acaba por gerar um novo valor profissional, o da polivalência.

A polivalência como valor foi identificada em alguns dos discursos analisados, detectado tanto na defesa do profissional multifunção como uma realidade mercadológica ( $\mathrm{O}$ jornalista que entende de rádio como ninguém, 2016), tanto na compreensão de que a absorção de funções técnicas, como edição de áudio, era algo desejado pelos jornalistas, que passaram a ter mais controle da qualidade da notícia produzida (O jornalista que não atua mais como jornalista, 2016). O próprio entendimento da polivalência como incorporada à rotina produtiva (O jornalista que atua em diversas frentes, 2016) revelou o quanto esse valor estava presente no ambiente radiofônico.

Outros valores, entretanto, não foram identificados na análise dos relatos destes jornalistas. A liberdade e a autoridade, valores antes explicitados, não surgiram como centrais nas entrevistas. A liberdade, explica-se, não está associada apenas à liberdade de imprensa, mas também a um valor intimamente ligado ao papel do jornalista na democracia nacional. Este valor, em decorrência da sobrecarga dos profissionais e da depreciação da profissão, que desde a decisão da não obrigatoriedade do diploma ${ }^{3}$ vem vivenciando transformações preocupantes no tratamento dado pelas empresas midiáticas, desapareceu em uma rotina que pouco deixa espaço para preocupações sociais, seja com o tratamento dado às notícias, seja na busca por informações mais apuradas.

Já a autoridade não surgiu na exposição dos jornalistas pelo fato de que estes não possuíam mais a primazia da informação. A disseminação de plataformas de publicação em virtude do barateamento das tecnologias digitais fez com que qualquer um, munido de um telefone celular e de internet, pudesse publicar os acontecimentos presenciados no dia a dia e trouxessem, muitas vezes, informações relevantes antes mesmo dos meios de comunicação tradicionais. Vale ressaltar, entretanto, que os jornalistas entrevistados consideraram que o trabalho realizado no meio radiofônico por eles diferia do realizado por internautas sem formação acadêmica. "O que diferencia a notícia que está sendo veiculada no rádio é a veracidade, a credibilidade. A gente checa a notícia antes de levá-la ao ar" (A jornalista com tempo de rádio, 2016). Assim, apesar da autoridade não se fazer mais presente na fala dos profissionais, a credibilidade ainda se evidencia.

Identificou-se, também, que a verdade, valor que permeia os códigos deontológicos da profissão, ainda se encontrava presente. Este valor está interligado à própria ética profissional e à formação do jornalista e sua atuação, portanto ele não é reconfigurado ou ocultado. Está inserido naturalmente na fala dos jornalistas e surge atrelado a outros valores, como o da credibilidade e da objetividade. Quando a jornalista afirmou que o diferencial do trabalho realizado por ela era a checagem dos fatos, este valor se evidenciou, assim como quando o entrevistado criticou as abordagens radicais de alguns colegas de profissão, que não deram espaço para dúvidas em seus trabalhos. Deste modo, a verdade surgiu como um valor que perpassou a construção da identidade do jornalista como tal.

A verdade está tão intrinsecamente ligada ao fazer profissional, que Benetti afirma ser por causa dos conceitos de verdade e credibilidade "que o jornalismo se constitui como campo de saber com as características expostas, que podem distingui-lo, no imenso universo da comunicação midiática, de tantos outros discursos" 
(BENETTI, 2008, p. 24). Porém, ressalta-se que este valor, como afirma Charaude$\mathrm{au}$, precisa ser relativizado quanto a sua aplicação, visto que no caso do jornalismo produz-se um efeito de verdade, ou seja, um discurso que "se realiza através de uma construção explicativa elaborada com a ajuda de uma instrumentação científica que se quer exterior ao homem (mesmo que seja ele quem a tenha construído)" (CHARAUDEAU, 2004, p. 49).

Por fim, apesar de haver outros valores que permeiam tanto as relações profissionais como produtivas, optou-se aqui por trazer apenas aqueles expressados pelos jornalistas entrevistados. Apesar de procurar expor as omissões observadas na análise, não foi possível abordar todos os valores relacionados à profissão, dando prioridade apenas para os considerados centrais (TRAQUINA, 2012), dada as limitações existentes em um paper.

Para melhor exposição dos resultados, disponibiliza-se abaixo quadro com a separação dos valores por aqueles: que se mantêm presentes, que não se evidenciaram e que surgem (ou ressurgem) na fala dos jornalistas. Observa-se que a reconfiguração de determinados valores e o surgimento de novos modifica o ethos do jornalista, que se desapodera de "sua aura de herói e passa a assumir o papel de um operário anônimo, parte de um sistema de produção jornalística taylorizado" (QUADROS; MOTTA, 2015, p. 6).

\section{Quadro 1: Valores Profissionais}

\begin{tabular}{|c|c|c|}
\hline VALOR & CARACTERÍSTICAS & ANÁLISE \\
\hline VERDADE & $\begin{array}{l}\text { Está atrelada à ética jor- } \\
\text { nalística. O profissional se } \\
\text { compromete com a verda- } \\
\text { de dos fatos. }\end{array}$ & $\begin{array}{l}\text { Ainda presente. Não so- } \\
\text { freu reconfigurações e não } \\
\text { foi ocultado no discurso. }\end{array}$ \\
\hline OBJETIVIDADE & $\begin{array}{l}\text { Relaciona-se à imparcia- } \\
\text { lidade. A primazia é dos } \\
\text { fatos e não da opinião. }\end{array}$ & $\begin{array}{l}\text { Ainda se faz presente } \\
\text { como valor, mas com } \\
\text { reconfigurações signifi- } \\
\text { cativas. A total neutrali- } \\
\text { dade do jornalista não é } \\
\text { considerada como algo } \\
\text { possível. }\end{array}$ \\
\hline CRITICIDADE & $\begin{array}{l}\text { Postura crítica frente aos } \\
\text { acontecimentos. Necessi- } \\
\text { dade de considerar os fatos } \\
\text { como plurais, exigindo do } \\
\text { jornalista apuração ampla. }\end{array}$ & $\begin{array}{l}\text { Este valor surge das } \\
\text { reconfigurações obser- } \\
\text { vadas na objetividade. } \\
\text { Justamente por consi- } \\
\text { derar que os fatos são } \\
\text { complexas ações sociais, } \\
\text { que possuem diversas } \\
\text { possibilidades de aborda- } \\
\text { gem, a criticidade surge } \\
\text { como valor que auxilia } \\
\text { na preservação dos fatos } \\
\text { concretos. }\end{array}$ \\
\hline
\end{tabular}




\begin{tabular}{|c|c|c|}
\hline CREDIBILIDADE & $\begin{array}{l}\text { Valor que se relaciona em } \\
\text { demasia ao ethos do jorna- } \\
\text { lista, de indivíduo autori- } \\
\text { zado socialmente a servir } \\
\text { como ponte entre os aconte- } \\
\text { cimentos e a população. }\end{array}$ & $\begin{array}{l}\text { Apesar das transforma- } \\
\text { ções da realidade profis- } \\
\text { sional, este valor ainda } \\
\text { está presente. Os jornalis- } \\
\text { tas entrevistados conside- } \\
\text { ram ter papel importante } \\
\text { a cumprir e que estão em } \\
\text { posição diferenciada dos } \\
\text { que se propõem a fazer o } \\
\text { mesmo, mas sem a for- } \\
\text { mação dos canais oficiais, } \\
\text { como a universidade. }\end{array}$ \\
\hline LIBERDADE & $\begin{array}{l}\text { Valor relativo a dois aspec- } \\
\text { tos da atuação profissional. } \\
\text { O primeiro alusivo à liber- } \\
\text { dade da imprensa em di- } \\
\text { vulgar os fatos. O segundo, } \\
\text { e analisado aqui, referente } \\
\text { ao papel do jornalista como } \\
\text { pilar democrático. }\end{array}$ & $\begin{array}{l}\text { Este valor não surgiu } \\
\text { durante a análise reali- } \\
\text { zada. Considera-se que } \\
\text { tal omissão ocorreu em } \\
\text { decorrência da sobrecar- } \\
\text { ga dos profissionais e da } \\
\text { depreciação da profissão. } \\
\text { Assim, os jornalistas } \\
\text { atendem as demandas } \\
\text { emergenciais da rotina } \\
\text { produtiva, sem comtem- } \\
\text { plarem o aspecto social e } \\
\text { político da profissão. }\end{array}$ \\
\hline AUTORIDADE & $\begin{array}{l}\text { A autoridade alude ao papel } \\
\text { do jornalista como aquele } \\
\text { que possui acesso e auto- } \\
\text { rização para estar onde os } \\
\text { fatos ocorrem, seja aonde } \\
\text { for. }\end{array}$ & $\begin{array}{l}\text { Outro valor que não foi } \\
\text { identificado na análise. } \\
\text { Entende-se que a proli- } \\
\text { feração de plataformas } \\
\text { de publicação digitais, } \\
\text { a publicação de notícias } \\
\text { por qualquer um munido } \\
\text { de um smartphone e a } \\
\text { não obrigatoriedade do } \\
\text { diploma tenham relação } \\
\text { ao desaparecimento deste } \\
\text { valor. }\end{array}$ \\
\hline POLIVALÊNCIA & $\begin{array}{l}\text { A polivalência, ou o jor- } \\
\text { nalismo multifunção, é a } \\
\text { absorção, pelo jornalista, de } \\
\text { atividades externas das pre- } \\
\text { vistas no cargo ocupado e a } \\
\text { produção para plataformas } \\
\text { diversas, que vão além da } \\
\text { qual ele foi contratado. }\end{array}$ & $\begin{array}{l}\text { Tal valor surge da neces- } \\
\text { sidade de os jornalistas } \\
\text { se manterem em um } \\
\text { mercado cada vez mais } \\
\text { pulverizado e enxuto. A } \\
\text { polivalência como valor } \\
\text { evidencia o cenário preo- } \\
\text { cupante em que os jorna- } \\
\text { listas estão inseridos. }\end{array}$ \\
\hline
\end{tabular}

Fonte: elaboração da autora

\section{Considerações finais}

Alguns valores, como o da objetividade, estão tão entranhados no fazer profissional que todos os entrevistados sabiam determiná-lo como prementes na definição de um bom fazer jornalístico. Porém, em decorrência das transformações ocorridas no campo de trabalho destes profissionais, o ethos modificou-se, adaptando-se a um mercado mais pulverizado, concorrido e desvalorizado. Novos valores surgiram na construção identitária do jornalista, que precisou passar a considerar como fundantes concepções que o manteriam no mercado, a exemplo da polivalência. 
Outros valores desapareceram do discurso dos jornalistas, principalmente devido ao fato do mercado estar debilitado pelo surgimento de diversas plataformas de publicação, acessíveis a uma gama ampla de interessados. Assim, a autoridade do jornalista se enfraquece, visto a notícia estar disponível por novos meios, e a liberdade, relacionada ao papel do jornalista como fundante de uma democracia, desvanece do discurso destes profissionais, seja pela normatização da exigência por produtores de conteúdo ou pela formatação da produtividade, que encontra na terceirização ${ }^{4}$ do conteúdo uma forma de baratear os gastos de uma redação.

Estas transformações modificam, também, etapas do processo produtivo que antes eram consolidadas, importantes para a teoria do newsmaking, exigindo que as pesquisas de teoria do jornalismo se adequem ao novo cenário. A exemplo cita-se o jornalista que está cada vez mais solitário na prática produtiva, atendendo a demandas diversas que o faz agir mais como um produtor de conteúdo. Deste modo, a notícia, que antes era produzida por três ou quatro profissionais, hoje é estruturada apenas por um.

Identificou-se, por fim, que os jornalistas entrevistados demonstram insegurança quanto ao futuro profissional, não conseguindo determinar claramente o que caracteriza o fazer jornalístico. Sentimento justificado por "um campo profissional extremamente mutante, incerto, movediço, tanto do ponto de vista da própria identidade do jornalismo, quanto das possibilidades futuras de 'uma profissão que não existe"” (MARCONDES FILHO, 2009, p. 58).

\section{REFERÊNCIAS}

BARDIN, Laurence. Análise de Conteúdo. São Paulo: 70, 2016.

BENETTI, Marcia. O jornalismo como gênero discursivo. Revista Galáxia, São Paulo, n. 15, 2008, pp. 13-28.

BURGE, Tyler. Content preservation. The philosophical review, Durham, Duke University, v. 102, n. 4, p.457-488, 1993.

CHARAUdEAU, Patrick. Gênero de discurso. In: CHARAUDEAU, Patrick; MAINGUENEAU, Dominique (Org.). Dicionário de análise do discurso. São Paulo: Contexto, 2004.

DEL BIANCO, Nélia. Radiojornalismo em mutação: a influência tecnológica e cultural da Internet na transformação da noticiabilidade no rádio. São Paulo. Tese (Doutorado em Ciências da Comunicação) - Universidade de São Paulo, São Paulo, 2004.

FERRARETTO, Luiz Artur; KISCHINHEVSKY, Marcelo. Rádio e convergência: uma abordagem pela economia política da comunicação. Revista FAMECOS, Porto Alegre, v. 17, n. 3, 2010, pp.173-180.

FÍGARO, Roseli. Perfis e Discursos de Jornalistas no Mundo do Trabalho. In: FÍGARO, Roseli; NONATO, Cláudia; GROHMANN, Rafael. As mudanças no mundo do trabalho do jornalista. São Paulo: Salta, 2013.

JENKINS, Henry. Cultura da Convergência. São Paulo: Aleph, 2009.

KISCHINHEVSKY, Marcelo. O Rádio sem Ondas: a convergência digital e novos desafios na radiofusão. Rio de Janeiro: E-papers, 2007.

KISCHINHEVSKY, Marcelo. Rádio e Mídias Sociais: mediações e interações radiofônicas em plataformas digitais de comunicação. Rio de Janeiro: Mauad X, 2016.
${ }^{4}$ Esta terceirização relaciona-se tanto ao fato do jornalista se pautar pelos meios concorrentes, como pela enorme quantidade de matérias produzidas por agências de notícias que estão sendo inseridas nas redações. 
LISBOA, Sílvia. Jornalismo e a credibilidade percebida pelo leitor: independência, imparcialidade, objetividade, honestidade e coerência. Dissertação (Mestrado em Comunicação). Universidade Federal do Rio Grande do Sul. Porto Alegre, 2012. Disponível em: <http://www.lume.ufrgs.br/handle/10183/54507>.

LISBOA, Sílvia; BENETTI, Marcia. O jornalismo como crença verdadeira justificada. Brazilian Journalism Research, v.11, 2015, pp. 10-29.

LOPEZ, Debora Cristina. Marcos tecnológicos do radiojornalismo no Brasil: uma revisão histórica. In: Encontro Nacional de História da Mídia, 2009, Fortaleza. Anais do VII Encontro Nacional de História da Mídia. São Paulo: Rede Alcar, 2009.

MAIA, Bárbara. O Processo de Convergência no Radiojornalismo: transformações profissionais na rádio CBN-Curitiba. 144 p. Dissertação (Mestrado em Comunicação) Universidade Federal do Paraná, Curitiba, 2017.

MARCONDES FILHO, Ciro. Ser jornalista: o desafio das tecnologias e o fim das ilusões. São Paulo: Paulus, 2009.

MIELNICZUK, Luciana. Webjornalismo de Terceira Geração: continuidades e rupturas no jornalismo desenvolvido para a web. In: XXVII - INTERCOM, 2004, Porto Alegre, 2004.

MORETZSONH, Sylvia Debossan. O “Novo Ritmo da Redação” de O Globo: a prioridade ao jornalismo digital e seus reflexos na condição de trabalho e produção da notícia. Revista Parágrafo, v. 2, 2014, pp. 146-165.

ORTIZ, Renato. Cultura e Modernidade. Brasiliense: São Paulo, 1991.

PALACIOS, Marcos. Ferramentas para Análise de Qualidade no Ciberjornalismo. Covilhã, Portugal. LabCom Books, 2011.

PENA, Felipe. Teorias do Jornalismo. Contexto: São Paulo, 2005.

PRATA, Nair. Webradio: novos gêneros, novas formas de interação. 2008. 395 f. Tese (Doutorado em Linguística Aplicada) - Faculdade de Letras, Universidade Federal de Minas Gerais, Belo Horizonte. 2008.

PRIMO, Alex. Crítica da Cultura da Convergência: participação ou cooptação? In: DUARTE, E. B.; CASTRO, M. L. D. (Org.). Convergências Midiáticas: Produção Ficcional - RBS TV. Sulina, Porto Alegre, 2010. pp. 21-32.

QUADROS, Claudia Irene de. Periodistas y diarios electrónicos: las exigencias profesionales en la red. Estudio de los casos El País Digital, El Mundo del Siglo XXI, Netestado y O Globo On. Tese de Doutorado. Universidad de La Laguna, 1999.

QUADROS, Mirian Redin de; MOTTA, Juliana. A participação do ouvinte e a identidade do jornalista de rádio: a percepção dos profissionais de Santa Maria/RS. In: $10^{\circ}$ Encontro Nacional de História da Mídia, 2015, Porto Alegre. Anais... Porto Alegre: Alcar, 2015.

RÜDIGER, Francisco. As teorias da cibercultura: perspectivas, questões e autores. Porto Alegre: Sulina, 2013.

TÁRCIA, Lorena Péret Teixeira. Tramas da Convergência: Cartografia de dispositivos acoplados na cobertura dos Jogos Olímpicos de Verão pela BBC em 2012. 354 p. Tese (Doutorado em Comunicação) - Universidade Federal de Minas Gerais, Belo Horizonte, 2015.

TRAQUINA, Nelson. Teorias do Jornalismo: porque as notícias são como são. Insular: Florianopólis, 2012.

WOLF, Mauro. Teorias da Comunicação. Lisboa, Presença: 1999. 